\title{
PINNIPEDS HAVE SOMETHING TO SAY ABOUT SPEECH AND RHYTHM
}

\author{
ANDREA RAVIGNANI ${ }^{* 1,2,3}$, MAXIME GARCIA ${ }^{4}$, STEPHANIE GROSS $^{5}$, KOEN DE $^{2}$ \\ REUS $^{1}$, NIENKE HOEKSEMA ${ }^{1}$, ANA RUBIO-GARCIA ${ }^{1}$, and BART DE BOER ${ }^{2}$ \\ *Corresponding Author: andrea.ravignani@gmail.com \\ ${ }^{1}$ Research Department, Sealcentre Pieterburen, Pieterburen, Netherlands \\ ${ }^{2}$ Artificial Intelligence Lab, Vrije Universiteit Brussel, Brussels, Belgium \\ ${ }^{3}$ Language and Cognition Department, Max Planck Institute for Psycholinguistics, \\ Nijmegen, Netherlands \\ ${ }^{5}$ ENES Lab/Neuro-PSI, CNRS UMR9197, University of Lyon/Saint Etienne, \\ Saint-Etienne, France \\ ${ }^{5}$ Institute for Terrestrial and Aquatic Wildlife Research, University of \\ Veterinary Medicine Hannover, Foundation, Buesum, Germany
}

Understanding the origins and evolution of human speech requires multidisciplinary approaches. One approach consists in investigating animals' capacities for sound production. In particular, the function, ontogeny, mechanisms and flexibility of vocal production in other animals can shed light, by homology or analogy, on early stages of vocal production in the human lineage. Historically, comparative work has been performed on non-human primates or avian species. However, at least four other taxonomic groups show (i) greater phylogenetic proximity to humans than birds, and (ii) on average, more developed vocal production learning capacities than primates. These groups are pinnipeds (true seals, sea lions, fur seals, and walrus), bats, cetaceans, and elephants (Ralls et al., 1985; Janik \& Slater, 2000; Reichmuth \& Casey, 2014; Mathevon et al., 2017). Here we focus on pinnipeds and argue that, although this research lags decades behind avian and primate work, pinniped work has much to offer to understand the origins of human speech and music (Ravignani et al., 2016). In this contribution, we: (i) critically review available evidence on pinnipeds' capacities for vocal learning and rhythm (Reichmuth \& Casey, 2014; Ravignani et al., 2016), (ii) present longitudinal 
data on vocal development in harbour seal pups, including a case study of spontaneous vocal mimicry (de Reus, 2017), (iii) discuss preliminary evidence on pinnipeds' abilities for 'turn-taking' (Ravignani, in review), obtained from multitrack group recordings and playback experiments, and (iv) complement acoustic studies with anatomical findings on pinnipeds' larynx and vocal tract (Ravignani et al., 2017). We show how acoustic features in seal vocalizations change with age and sex, suggest that seals time their calls based on a 'selfish herd' mechanism (Hamilton, 1971; Ravignani 2014), and argue for anatomical similarities between the human and harbour seal phonatory apparati. Together, our findings suggest that pinnipeds' abilities to produce sounds, and time them precisely, are more developed than previously surmised (Mathevon et al., 2017).

\section{Acknowledgements}

This project has received funding from the European Union's Horizon 2020 research and innovation programme under the Marie Skłodowska-Curie Grant agreement No. 665501 with the research Foundation Flanders (FWO) (Pegasus2 Marie Curie fellowship 12N5517N awarded to A.R.), a visiting fellowship in Language Evolution from the Max Planck Society (awarded to A.R.), and ERC Grant [283435] ABACUS (awarded to B.d.B.). M.G. was supported by a postdoctoral fellowship from the Fyssen Foundation. We are grateful to M.Anichini, P.Cook, H.Honing, S.Kotz, M.Mendez-Arostegui, R.Sonnweber for advice and support.

\section{References}

Hamilton, W. D. (1971). Geometry for the selfish herd. Journal of theoretical Biology, 31(2), 295-311.

Janik, V. M., \& Slater, P. J. (2000). The different roles of social learning in vocal communication. Animal Behaviour, 60(1), 1-11.

Khan, C. B., Markowitz, H., McCowan, B. (2006). Vocal development in captive harbor seal pups, Phoca vitulina richardii: Age, sex, and individual differences. The Journal of the Acoustical Society of America, 120(3):16841694.

Mathevon, N., Casey, C., Reichmuth, C., \& Charrier, I. (2017). Northern Elephant Seals Memorize the Rhythm and Timbre of Their Rivals' Voices. Current Biology.

Ralls, K., Fiorelli, P., \& Gish, S. (1985). Vocalizations and vocal mimicry in captive harbor seals, Phoca vitulina. Canadian Journal of Zoology, 63(5), 1050-1056. 
Ravignani, A., Fitch, W. T., Hanke, F. D., Heinrich, T., Hurgitsch, B., Kotz, S. A., Scharff, C., Stoeger, A. \& de Boer, B. (2016). What pinnipeds have to say about human speech, music, and the evolution of rhythm. Frontiers in neuroscience, 10.

Ravignani, A., Gross, S., Garcia, M., Rubio-Garcia, A., \& de Boer, B. (2017). How small could a pup sound? The physical bases of signaling body size in harbor seals. Current Zoology.

Ravignani, A. (2014). Chronometry for the chorusing herd: Hamilton's legacy on context-dependent acoustic signalling - a comment on Herbers (2013). Biology letters, 10(1), 20131018.

Ravignani, A. (in review). Spontaneous rhythms in a harbor seal pup calls. $B M C$ Research Notes.

Reichmuth, C., \& Casey, C. (2014). Vocal learning in seals, sea lions, and walruses. Current opinion in neurobiology, 28, 66-71.

de Reus, K. (2017): Talking seals: Vocal development in Eastern Atlantic harbour seal pups (Phoca vitulina vitulina). MSc. Royal Veterinary College, University of London. 